\title{
Canada falls short on safeguarding its drug supply
}

\author{
Matthew B. Stanbrook MD PhD, Rosemary M. Killeen RPh BScPhm
}

$\mathrm{D}$ rug shortages, a global problem affecting pharmacies and hospitals across Canada, have become frequent, largely unpredictable and widespread since mid2010. Occasional drug shortages are not new, but the number and variety of drugs involved recently is unprecedented. This situation will not improve in the foreseeable future without major changes in how Canadian governments, federal, provincial and territorial, respond to it.

Drug classes particularly affected have included antiepileptics (e.g., phenytoin), chemotherapy agents (e.g., docetaxel), antibiotics (e.g., amoxicillin/clavulanate and cephalexin) and anesthetic agents (e.g., propofol). Most drugs recently affected are generic, particularly sterile injectable medications. Consequences to Canadians have included worsening of chronic medical conditions, medical errors, adverse effects from substituted new drugs, cancellation of surgeries and medical procedures, and increased costs to patients and the health care system. ${ }^{1-3}$

Although the causes of drug shortages are myriad and complex, ${ }^{1}$ Canada's lack of preparedness for and ability to cope with this problem seem more readily apparent. One salient feature is the absence of integrated, coordinated national leadership on drug policy in Canada. Despite warnings from a variety of stakeholders in 2010 and 2011, the federal government's response to this alarming problem has, to date, been inadequate. Little legislative attention was paid to this issue until the sudden, unexpected shutdown of production in early 2012 at Sandoz, the exclusive supplier of many generic injectable drugs in Canada, prompted debate in Parliament and hearings at the House of Commons Standing Committee on Health. ${ }^{4}$

Other countries have taken more decisive action. Europe has mandated advance reporting of drug shortages for over a decade. ${ }^{1}$ In the US, President Barack Obama issued an executive order last fall requiring all pharmaceutical manufacturers to inform the Food and Drug Administration in advance of any impending potential drug shortages. This initiative has already been credited with a 6-fold increase in manufacturer reports and a doubling of drug shortages that have been prevented. ${ }^{5}$ Legislation passed by the US Congress in June 2012 gave the FDA further regulatory authority in this area. ${ }^{6}$ Yet similar government action has been absent in Canada, where the Minister of Health, rather than giving Health Canada the authority to require mandatory reporting, is instead relying on industry to set up its own voluntary reporting system. Only in March 2012 did the House of Commons pass a nonbinding Opposition motion calling for mandatory reporting and a national drug supply strategy. Tellingly, the report of the Standing Committee on Health endorses neither recommendation. ${ }^{4}$

If governments do not start showing leadership on this issue, who will act in the interest of Canadian patients? Canada cannot cope adequately with a problem of this scope with 14 regional health systems operating independently. Federal involvement in this issue is unavoidable, given direct federal responsibility for some health care delivery (e.g., to Aboriginal communities, military personnel and inmates of federal prisons), not to mention drug patent laws and the Canada Health Act. Moreover, regulatory authority for drugs belongs to Health Canada, which only belatedly has started to inform the public about drug shortages and to expedite approval of alternate suppliers of drugs that have been in short supply. Indeed, delays at Health Canada in approving new drugs and production process improvements for existing drugs have likely exacerbated drug shortages. ${ }^{1,4}$

As a first step toward a national approach, a mandatory reporting system for impending shortages should be created and maintained, so that health care stakeholders at all levels have adequate and timely information with which to make decisions. With coordinated national leadership, Canada could potentially implement other strategies to mitigate shortages of vital supplies: expanding the national pharmaceutical stockpile to include more drugs deemed essential to health care delivery; requiring that supply contracts for all essential drugs be made with a minimum of 2 suppliers; or establishing contingency plans to share supplies across the country and restock from alternate international suppliers quickly if a shortage occurs. National influence and legislative authority could also provide incentives to lead pharmaceutical manufacturers away from business practices that drive shortages. Meanwhile, provincial and territorial governments must do more to activate their own capacity for coordinated action, such as through the Council of the Federation.

The people of Canada deserve greater responsiveness and action from their elected officials to safeguard the supply of some of the most critical components of health care delivery. It is ridiculous and intolerable that a wealthy, developed nation like Canada cannot reliably provide medicines to its people.

For references, see Appendix 1, available at www.cmaj.ca/lookup/suppl /doi:10.1503/cmaj.121196/-/DC1

Competing interests: Rosemary Killeen has received an honorarium from Merck Frosst for speaker/moderator duties. She has served as a reviewer for MediResource Inc. and is a community pharmacist for Shoppers Drug Mart. See www.cmaj.ca/site/misc/cmaj_staff.xhtml for Matthew Stanbrook's competing interests.

Affiliations: Matthew Stanbrook is Deputy Editor, CMAJ, and Rosemary Killeen is Editor-in-Chief/Deputy Publisher, Canadian Pharmacists Journal.

Correspondence to: $C M A J$ editor, pubs@cmaj.ca

CMAJ 2012. DOI:10.1503/cmaj.121196

All editorial matter in CMAJ represents the opinions of the authors and not necessarily those of the Canadian Medical Association. 